\title{
Impact of Radical and Partial Nephrectomy on Renal Function in Patients with Renal Cancer
}

\author{
R.K. Krebs C.Andreoni V. Ortiz \\ Division of Urology, Federal University of São Paulo, São Paulo, Brazil
}

\begin{abstract}
Key Words
Renal cancer - Renal function - Chronic renal disease . Partial nephrectomy $\cdot$ Radical nephrectomy
\end{abstract}

\begin{abstract}
Objective: To evaluate renal function in renal cancer patients undergoing radical nephrectomy (RN) or partial nephrectomy (PN) (open or laparoscopic - ORN, OPN, LRN or LPN) and to identify risk factors contributing to renal function loss. Methods: We analysed 228 consecutive renal cancer patients admitted for OPN, LPN, ORN or LRN. The variables analysed were age, gender, weight, type of surgery (radical versus partial), type of surgical access (open versus laparoscopic), preoperative renal function and history of hypertension, diabetes or malignancy. Absolute renal function was calculated as the difference in glomerular filtration rate $(\triangle G F R)$ between the renal function before $\left(G F R_{0}\right)$ and 12 months after surgery $\left(G R_{12}\right)$. The relative renal function of patients undergoing $\mathrm{PN}$ and $\mathrm{RN}$ was evaluated by the change in chronic kidney disease stage. Results: LRN caused the greatest loss in absolute renal function, followed by ORN, LPN and OPN. A GFR of $\geq 60 \mathrm{ml} / \mathrm{min}$ was noted for $90(68.7 \%)$ patients before and 65 (49.6\%) patients after RN and for 80 (82.5\%) patients before and 74 (76.3\%) patients after PN. The chronic kidney disease stage dropped to 4 or 5 in the case of $6(4.6 \%)$ patients who underwent RN and 2 (2.1\%) patients who underwent PN. Multivariate analysis revealed that only
\end{abstract}

preoperative weight and type of surgery (radical versus partial) had a significant impact on renal function. Conclusion: Renal function significantly decreased in patients undergoing RN, irrespective of the access route. Patients with preoperative poor renal function are at risk of postoperative endstage renal disease.

(c) 2014 S. Karger AG, Basel

\section{Introduction}

Policies for the improvement of public health, especially those established over the last 50 years, have significantly increased the life expectancy of the population in many countries [1]. Several policies, from immunisation programs to the establishment of protocols for the care of patients with acute myocardial infarction and stroke, have contributed greatly to increasing the survival of individuals [2]. As a result, a large contingent of individuals has access to several modes of diagnosis and treatment. The case of kidney tumours is a clear example of how wide access to diagnostic tools can help in altering the natural history of disease. Until 1960 , about $70 \%$ of renal tumours were detected only when they caused signs and symptoms such as haematuria or a palpable mass [3]. With limited diagnostic and treatment options, the mortality rates were extremely high [4]. After 40 years, this situation has dramatically changed. Today, between 60 and $70 \%$ of renal

\section{KARGER}

E-Mail karger@karger.com

www.karger.com/uin
(C) 2014 S. Karger AG, Basel

0042-1138/14/0924-0449\$39.50/0
Rodrigo K. Krebs

Division of Urology, Federal University of São Paulo

R. Napoleão de Barros, $715,2^{\circ}$ andar

04024-002 São Paulo (Brazil)

E-Mail rodrigo.k.krebs@gmail.com 
masses are identified when $<4 \mathrm{~cm}$ in diameter and almost asymptomatic [5]. In addition, the forms of treatment have also evolved: since the mid-1980s, partial nephrectomy (PN) started gaining ground, and during the 1990s, the laparoscopic approach was introduced and rapidly absorbed into clinical practice. More recently, laparoscopic PN (LPN) and other minimally invasive techniques have also contributed to the progress in the treatment of renal tumours. Despite all these technical advances in the fields of diagnosis and treatment, the mortality rates in patients with renal tumours have actually increased in the recent years [6]. Although studies have not completely elucidated the biological behaviour of renal tumours, the actual reasons for this increased mortality cannot be linked directly to the tumour, but to clinical factors such as age, obesity, diabetes, hypertension and, especially, history of end-stage renal disease [7]. Among these factors, chronic renal failure plays a leading role because it is directly associated with an increased risk of death events and cardiovascular hospitalisation [8]. Therefore, any therapeutic method that contributes to the preservation of renal tissue has a direct impact on the survival of patients with kidney tumours [9].

Under these circumstances, there is growing interest in the preservation of renal function not only in healthy subjects but also in populations at risk - those elderly and those with cardiovascular diseases, diabetes, obesity and/ or hypertension. This study aimed to assess the renal function of patients with renal tumours who underwent radical nephrectomy $(\mathrm{RN})$ or PN. Further, we also sought to verify whether the surgical access (open or laparoscopic) has any influence on renal function loss.

\section{Materials and Methods}

After obtaining approval from the institutional review board, we retrospectively reviewed our institution's database for data on 299 consecutive renal cancer patients who underwent PN or RN during a 7-year period. We excluded patients with a serum creatinine level $>2.5 \mathrm{mg} / \mathrm{dl}$ or a glomerular filtration rate $(\mathrm{GFR})<30 \mathrm{ml} /$ min, those who were lost to follow-up or died during the study period, and those who had a solitary kidney.

Data on the remaining 228 individuals were obtained for the following factors: gender, age, weight, serum creatinine level, size of tumour on computed tomography, pathological stage and presence of hypertension or diabetes. Renal function was determined by the Cockcroft-Gault formula before $\left(\mathrm{GFR}_{0}\right)$ and 12 months after the operation $\left(G_{F R}\right)$. The difference between $G_{12}$ and $\mathrm{GFR}_{0}$ was calculated to evaluate the loss of renal function. To identify patients who had renal function loss, we assessed them as per the National Kidney Foundation staging system and categorised patients having a lower stage at the end of the evaluation period as having renal function loss. We classified the patients into three groups according to $\mathrm{GFR}_{0}$ : stage 1 , for GFR $\geq 90 \mathrm{ml} / \mathrm{min}$; stage 2, for GFR 60-89 $\mathrm{ml} / \mathrm{min}$; and stage 3, for GFR 30-59 $\mathrm{ml} / \mathrm{min}$. Patients were initially divided into four groups according to the type of surgery: open PN (OPN; $n=15)$, open RN (ORN; $n=92)$, LPN $(\mathrm{n}=82)$ and laparoscopic RN (LRN; $\mathrm{n}=39)$. All patients in the OPN group were subjected to cold ischemia with the kidney packed on ice and the hilum controlled with Satinsky or Bulldog clamp, while all those in the LPN group were subjected to warm ischemia with laparoscopic Bulldog clamp without any cold ischemia technique. We evaluated the effect of the type of surgery (partial or radical) and the type of surgical access (open or laparoscopic) on the absolute variation of GFR ( $\triangle \mathrm{GFR})$, after accounting for the effect of hypertension, diabetes, pathological findings, gender, age and preoperative weight. Categorical values were compared using $\chi^{2}$ statistics, while quantitative variables were assessed using Student's $t$ test or analysis of variance, with $p<0.05$ being considered significant.

\section{Results}

The preoperative characteristics of the overall patient sample are shown in table 1. Except for the OPN group, all the others consisted to $>50 \%$ of men. Median age was similar in all groups. Serum creatinine level was slightly higher in the OPN group than in the others $(\mathrm{p}<0.001)$. Preoperative weight was similar in all groups, as was the incidence of hypertension $(\mathrm{p}=0.914)$ and diabetes $(\mathrm{p}=$ 0.084 ). Median tumour size differed according to the type of surgery: $\mathrm{PN}$ patients had smaller tumours than $\mathrm{RN}$ patients. On pathological analysis, the LPN group had the highest incidence of benign tumours (30.5\%), followed by the OPN group (20.0\%). In both the ORN and LRN groups, the incidence of malignant tumours was $>90 \%$.

The histological findings showed that clear cell carcinoma was the most common cancer, its incidence varying from 41.03 to $66.67 \%$. None of the patients in the PN group had urothelial carcinoma. The number of patients at stage 1 was higher in the PN group than in the RN group, since partial surgery is performed more frequently in patients with masses with diameters $<4 \mathrm{~cm}$. Among the RN groups, the distribution of pathological stages was homogeneous.

\section{Renal Function}

Table 2 shows the evolution of renal function over the period analysed. The OPN and LPN groups showed low $\triangle$ GFR variation, and the LRN group showed the highest $\Delta$ GFR at $-21.28 \pm 19.10 \mathrm{ml} / \mathrm{min}$. The difference in the change of variation of creatinine clearance $(\Delta \mathrm{GFR})$ between the OPN and LPN groups was not statistically significant ( $\mathrm{p}=0.889)$, but that between the ORN and LRN groups was $(\mathrm{p}<0.001)$. 
Table 1. Baseline histological and pathological data

\begin{tabular}{|c|c|c|c|c|c|}
\hline & \multicolumn{2}{|l|}{$\mathrm{PN}$} & \multicolumn{2}{|l|}{$\mathrm{RN}$} & \multirow[t]{2}{*}{$\mathrm{p}$} \\
\hline & OPN & LPN & ORN & LRN & \\
\hline $\mathrm{n}$ & 15 & 82 & 92 & 39 & \\
\hline Male sex & $9(40 \%)$ & $47(57 \%)$ & $50(54 \%)$ & $27(69 \%)$ & 0.464 \\
\hline Age, years & $58 \pm 11$ & $54 \pm 14$ & $56 \pm 15$ & $55 \pm 11$ & 0.606 \\
\hline Preoperative creatinine & $1.27 \pm 0.3$ & $0.99 \pm 0.2$ & $1.17 \pm 0.3$ & $1.09 \pm 0.2$ & $<0.001$ \\
\hline \multicolumn{6}{|l|}{ Comorbidity } \\
\hline Hypertension & $7(47 \%)$ & $43(52 \%)$ & $45(49 \%)$ & $18(46 \%)$ & 0.914 \\
\hline Diabetes & $61(7 \%)$ & $5(6 \%)$ & $17(18 \%)$ & $5(13 \%)$ & 0.084 \\
\hline \multicolumn{6}{|l|}{ Preoperative weight, kg } \\
\hline Females & $66 \pm 14$ & $68 \pm 11$ & $68 \pm 13$ & $69 \pm 12$ & 0.949 \\
\hline Males & $73 \pm 12$ & $82 \pm 10$ & $78 \pm 12$ & $82 \pm 14$ & 0.090 \\
\hline Tumour size, $\mathrm{cm}$ & $3.8 \pm 2.7$ & $3.4 \pm 1.5$ & $9.6 \pm 4.4$ & $6.4 \pm 1.9$ & $<0.001$ \\
\hline Malignant histology & $12(80 \%)$ & $57(70 \%)$ & $87(95 \%)$ & $38(97 \%)$ & $<0.001$ \\
\hline \multicolumn{6}{|l|}{ Pathological stage } \\
\hline I & $9(75 \%)$ & $53(93 \%)$ & $17(20 \%)$ & $21(55 \%)$ & \\
\hline II & $0(0 \%)$ & $4(7 \%)$ & $23(25 \%)$ & $8(21 \%)$ & \\
\hline III & $3(25 \%)$ & $0(0 \%)$ & $34(39 \%)$ & $5(13 \%)$ & \\
\hline IV & $0(0 \%)$ & $0(0 \%)$ & $13(15 \%)$ & $4(11 \%)$ & \\
\hline
\end{tabular}

Table 2. Absolute renal function values before and 12 months after the operation (statistical test: analysis of variance)

\begin{tabular}{|c|c|c|c|c|c|c|}
\hline & \multicolumn{2}{|l|}{$\mathrm{PN}$} & \multirow[t]{2}{*}{$\mathrm{p}$} & \multicolumn{2}{|l|}{$\mathrm{RN}$} & \multirow[t]{2}{*}{$\mathrm{p}$} \\
\hline & $\mathrm{OPN}$ & LPN & & ORN & LRN & \\
\hline $\mathrm{n}$ & 15 & 82 & & 92 & 39 & \\
\hline $\mathrm{GFR}_{0}, \mathrm{ml} / \mathrm{min}$ & $62.94 \pm 19.85$ & $89.71 \pm 27.33$ & 0.001 & $71.94 \pm 28.36$ & $85.92 \pm 33.12$ & 0.034 \\
\hline $\mathrm{GFR}_{12}, \mathrm{ml} / \mathrm{min}$ & $56.31 \pm 15.74$ & $82.27 \pm 25.63$ & 0.001 & $61.89 \pm 23.58$ & $64.64 \pm 23.32$ & 0.827 \\
\hline$\Delta \mathrm{GFR}$ & $-6.64 \pm 10.59$ & $-7.44 \pm 13.26$ & 0.889 & $-10.06 \pm 16.71$ & $-21.28 \pm 19.10$ & $<0.001$ \\
\hline GFR reduction & $10.55 \%$ & $8.29 \%$ & & $13.98 \%$ & $24.77 \%$ & \\
\hline
\end{tabular}

\section{Partial versus Radical Nephrectomy}

To analyse the impact of the type of surgery on renal function, patients were divided into two groups according to whether the surgery was partial or radical. $97 \mathrm{pa}$ tients underwent PN and $131 \mathrm{RN}$. The $\Delta \mathrm{GFR}$ in the PN group was $-7.31 \pm 12.84 \mathrm{ml} / \mathrm{min}$ and that in the $\mathrm{RN}$ group $-13.40 \pm 18.13 \mathrm{ml} / \mathrm{min}(\mathrm{p}=0.003)$.

\section{Hypertension and Diabetes}

The prevalence of hypertension in this sample was almost $50 \%(113 / 228)$. The $\Delta$ GFR of patients with hypertension was $-8.62 \pm 14.49$ and of those without hypertension $-12.96 \pm 17.78(\mathrm{p}=0.233)$. The prevalence of diabetes was approximately $10 \%(20 / 228)$ and the $\Delta$ GFR of diabetic patients was $-9.63 \pm 16.42$, whereas that of patients without diabetes was $-10.97 \pm 16.36(p=0.684)$.

Impact of Radical and Partial Nephrectomy on Patients with Renal Cancer

\section{Renal Function Evaluation by the Chronic Kidney}

Disease Stages

Table 3 shows the number of patients in each chronic kidney disease stage before and after surgery, classified according the type of surgery. Six (4.6\%) patients in the RN group and 2 (2.0\%) patients in the PN group showed progression to end-stage renal disease. A closer analysis of these $8 / 228$ (3.5\%) patients revealed that all of them presented low preoperative GFR and aggressive kidney tumours. Seven of these individuals had a $\mathrm{GFR}_{0}>40 \mathrm{ml} / \mathrm{min}$, which seemed to be the most important factor for worsening of renal function. The median age of these patients was 71.25 years, and most of the patients had undergone RN for clear cell carcinoma and were at pathological stage 3 .

Eight (3.5\%) patients in the study sample showed progression to end-stage renal disease at the end of the 
Table 3. Number of patients according the surgical approach ( $P N$ versus $\mathrm{RN}$ ) stratified by chronic kidney disease (CKD) stages

\begin{tabular}{|c|c|c|c|c|}
\hline \multirow[t]{2}{*}{ CKD stage } & \multicolumn{2}{|l|}{$\mathrm{RN}$} & \multicolumn{2}{|l|}{$\mathrm{PN}$} \\
\hline & $\begin{array}{l}\text { before } \\
\text { surgery }\end{array}$ & $\begin{array}{l}12 \text { months } \\
\text { after surgery }\end{array}$ & $\begin{array}{l}\text { before } \\
\text { surgery }\end{array}$ & $\begin{array}{l}12 \text { months } \\
\text { after surgery }\end{array}$ \\
\hline Stages 1 and $2(\geq 60 \mathrm{ml} / \mathrm{min})$ & $90(68.7 \%)$ & $65(49.6 \%)$ & $80(82.5 \%)$ & $74(76.3 \%)$ \\
\hline Stage $3(30-59 \mathrm{ml} / \mathrm{min})$ & $41(31.3 \%)$ & $60(45.8 \%)$ & $17(17.5 \%)$ & $21(21.6 \%)$ \\
\hline Stages 4 and $5(<30 \mathrm{ml} / \mathrm{min})$ & $0(0 \%)$ & $6(4.6 \%)$ & $0(0 \%)$ & $2(2.1 \%)$ \\
\hline
\end{tabular}

Table 4. Multivariate analysis

\begin{tabular}{ll}
\hline Variable & p value \\
\hline Surgery (partial or radical) & 0.0001 \\
Surgical access (open or laparoscopic) & 0.889 \\
Gender & 0.362 \\
Age & 0.971 \\
Preoperative weight & 0.003 \\
Hypertension & 0.064 \\
Diabetes & 0.817 \\
Malignant histology & 0.933 \\
\hline
\end{tabular}

12-month evaluation period. When only patients with $\mathrm{GFR}_{0}$ in stage 3 were isolated, this percentage increased to $14 \%$.

\section{Multivariate Analysis}

As shown in table 4, multivariate analysis revealed that the type of surgical access (laparoscopic or open) did not influence renal function over the period analysed. Gender, age, malignant histology, hypertension and diabetes did not alter renal function either. The type of surgery, i.e. whether the nephrectomy was partial or radical $(\mathrm{p}<$ $0.0001)$, and preoperative weight $(\mathrm{p}=0.003)$ were factors that contributed to renal function loss.

\section{Discussion}

Retrospective studies such as this are susceptible to a large number of biases. One is selection bias, which can be demonstrated by the discrepancy in the numbers of subjects in the groups. The OPN group had 15 patients, while the LPN group had 82. Similarly, the ORN group had 92 patients and the LRN group 39. This can be attributed to the fact that randomisation of the groups was impossible because the type of surgery ( $\mathrm{RN}$ or $\mathrm{PN})$ and the access (open or laparoscopic) were defined individually, in a caseby-case manner. However, even though there was intergroup discrepancy, the number of subjects studied did not show statistical differences between the variables. With regard to sex distribution, no significant male predilection was noted (range $40.0 \%$ in the OPN group to $69.2 \%$ in the LRN group; $\mathrm{p}=0.4648)$. The same result was obtained in the case of average age, which show no intergroup difference. An interesting finding is that the average age ranged between 54 and 57 years, which is lower than that classically described for renal tumours. This is perhaps due to easier access and more rapid diagnostic and therapeutic methods available currently; additionally, many patients were diagnosed incidentally during medical evaluation for other symptoms - a trend described globally [10]. The prevalence of hypertension in the study sample was similar in the different groups (range 46.2-52.4\%; $p=0.9148$ ); the frequency was twice that in the general Brazilian population, which is approximately $20 \%$ [11]. The prevalence of diabetes was higher, but not significantly $(\mathrm{p}=0.0843)$, in the groups that underwent RN (range 12.8-18.5\%) than the others. In the groups that underwent PN, the prevalence of diabetes was $6.1-6.7 \%$, which is slightly below that in the general population of Brazil [12]. The majority of patients with hypertension and diabetes had their medical conditions well controlled clinically, which may have contributed to our findings. A longer follow-up and larger sample could affect the results. The study also sought to assess the impact of the type of surgery and the surgical access on renal function in renal cancer patients.

Although numerous studies have been conducted on these factors, they are limited to comparisons between the types of surgery or surgical access.

Barlow et al. [13] analysed 174 and 102 patients who underwent RN and PN, respectively, by using the modification of diet in renal disease formula. The patients were categorised into two groups (GFR $\geq 60 \mathrm{ml} / \mathrm{min}$ or GFR $<60 \mathrm{ml} / \mathrm{min}$ ). In that study, $71 \%$ of the $\mathrm{RN}$ patients and 
$17 \%$ of the PN patients showed worsening of renal function over at least 3 months. Although the aforementioned study has a large study sample, it has some limitations, such as short follow-up time and categorising of patients into two groups.

Clark et al. [14] prospectively evaluated 37 patients who underwent RN (laparoscopic or open) and 26 who underwent PN (open approach only with cold ischemia). All patients with unilateral tumour and both kidneys were found to be normal in the study. Renal function was assessed preoperatively and at 3,6 and 12 postoperative months by creatinine clearance in 24-hour urine and the Cockcroft-Gault formula. The study showed that creatinine clearance dropped by $0.09 \mathrm{ml} / \mathrm{min}(6.1 \%)$ and $0.56 \mathrm{ml} / \mathrm{min}(31.6 \% ; \mathrm{p}<0.001)$ in the $\mathrm{RN}$ and $\mathrm{PN}$ groups, respectively. Regression analysis indicated that type of surgery, age and preoperative creatinine clearance were factors that affected renal function. A surprising result of our analysis was the highest $\triangle \mathrm{GFR}$ in the LRN group, as shown on table 2. An explanation for this is that in the LRN group the tumours were slight smaller than in the ORN group, so the remaining mass of normal parenchyma of the affected kidney was higher in the LRN group and did not require a compensatory hypertrophy of the contralateral kidney. Patients in the ORN group had greater tumours with less normal parenchyma in the compromised kidney, which may have reduced the $\mathrm{GFR}_{0}$. That is the reason for which we believe $\Delta$ GFR was higher in the LRN group than in the ORN group.

Luo et al. [15] performed a long-time analysis on oncological and clinical outcomes in 142 patients who underwent LRN and in 194 patients who underwent ORN. They did not find any differences in clinical variables during the 44 months of follow-up. As Luo et al., we noted that the absolute $\mathrm{GFR}_{12}$ of patients who underwent $\mathrm{RN}$ remained almost the same. In the groups who underwent $\mathrm{PN}$ (open or laparoscopic) we noted a significant intergroup difference in $\mathrm{GFR}_{0}$. The reasons contributing to this may have been the large tumours in the OPN group, initial poor renal function and the small number of patients. However, as seen in table 2, the $\Delta$ GFR between the open and laparoscopic groups was not statistically different.

Antoniewicz et al. [16] observed for 12 months the evolution of renal function in patients who had undergone $\mathrm{PN}$ and $\mathrm{RN}$ and found a higher reduction in the $\mathrm{RN}$ group than the PN group, as expected, but also concluded that in both groups the creatinine levels did not improve after the procedure. In our study, 8 patients $(3.8 \%$ of the sample) progressed to a GFR $<30 \mathrm{ml} / \mathrm{min}$ and thus became the group at risk for chronic renal failure. The most

Impact of Radical and Partial Nephrectomy on Patients with Renal Cancer significant factor for a poor outcome of renal function was low preoperative GFR. Among the 8 patients in this subgroup, 6 had undergone RN, 5 of them with open access; of these 8 patients, $75 \%$ were women aged between 66 and 80 years, and only $25 \%$ of patients had no comorbidities such as diabetes or hypertension.

Lau et al. [17] reported that in a cohort of 10 years, patients who underwent $\mathrm{RN}$ had a greater incidence of proteinuria (55.2 vs. $34.5 \%$ in the PN group), and the cumulative incidence of chronic kidney disease was 22.4 and $11.6 \%$ in the $\mathrm{RN}$ and $\mathrm{PN}$ groups, respectively $(\mathrm{p}=0.01)$. In our study the 2 patients who underwent $\mathrm{PN}$ and progressed to a $\mathrm{GFR}_{12}<30 \mathrm{ml} / \mathrm{min}$ had a $\mathrm{GFR}_{0}$ of $<60 \mathrm{ml} /$ min. Recently, the EORTC 30904 examined the impact of nephron-sparing surgery (NSS) to radical nephrectomy $(\mathrm{RD})$ in patients with renal tumors $\leq 5 \mathrm{~cm}$ and normal contralateral kidney. After a 6.7 years median follow-up they concluded NSS reduce the incidence of at least moderated renal function (GFR $<60$ ). The incidence of advanced kidney disease $(\mathrm{GFR}<30)$ was relative similar on NSS and RN group and the incidence of renal failure was almost identical (1.5\% on NSS group versus $1.6 \% \mathrm{RN}$ group) [18]. Although the small number of patients does not permit the establishment of definitive conclusions, the main factor for a poor outcome of renal function is low preoperative GFR.

In a study conducted on 1,169 patients, Lane et al. [19] concluded that low preoperative GFR, advanced age and tumour size were risk factors for poor outcome of renal function. Similarly, Takagi et al. [20] analysed a subgroup of 95 patients with preoperative chronic kidney disease. Of these, 51 underwent RN and 44 PN. Patients with a GFR of $45-59 \mathrm{ml} / \mathrm{min}$ submitted to PN had better evolution compared with patients submitted to RN. However, if GFR was 30-44 $\mathrm{ml} / \mathrm{min}$, both the $\mathrm{PN}$ and $\mathrm{RN}$ groups were at high risk of renal replacement therapy.

In our study, the warm ischemia during LPN or the cold ischemia during OPN did not contribute to a worsening of renal function $(\mathrm{p}=0.912)$. A study by Foyil et al. [21] with a follow-up of 12 months found that ischemia causes acute renal injury that apparently is reversible in patients without evidence of renal disease. Patients with risk factors (diabetes and hypertension) are at greater risk of loss of renal function. Another study by Godoy et al. [22] indicated that patients who underwent PN with a warm ischemia time $<40 \mathrm{~min}$ showed no significant loss of renal function, suggesting that the main factor for loss of kidney function was the degree of renal failure before surgery. A review of the literature concerning deterioration of renal function after PN suggests that not just isch- 
emia time, but also the quantity and quality of the renal parenchyma are important factors associated with a better recovery of renal function [23].

We believe that despite its limitations, the current study contributes to a better understanding of the importance of renal function in patients undergoing $\mathrm{PN}$ or $\mathrm{RN}$. It also suggests that the laparoscopic approach is safe and equally effective as open surgery in the management of renal tumours.

\section{Conclusions}

We conclude that 12 months after surgery, patients who had undergone $\mathrm{RN}$ had poorer renal function than those who had undergone PN. The type of surgical access (open or laparoscopic) did not influence the progression of renal function. Further, patients with a low preoperative GFR were found to be at a higher risk of accentuated renal function loss.

\section{References}

1 Ashton C, Bajekal M, Raine R: Quantifying the contribution of leading causes of death to mortality decline among older people in England, 1991-2005. Health Stat Q 2010;45:100-127.

-2 Epstein D, Jimenez-Rubio D, Smith PC, et al: Social determinants of health: an economic perspective. Health Econ 2009; 18:495-502.

3 Ritchie AW, deKernion JB: The natural history and clinical features of renal carcinoma. Semin Nephrol 1987;7:131-139.

4 Herr HW: A history of partial nephrectomy for renal tumors. J Urol 2005;173:705-708.

5 Russo P: Renal cell carcinoma: presentation, staging, and surgical treatment. Semin Oncol 2000;27:160-176.

6 6 Hollingsworth JM, Miller DC, Daignault S, et al: Rising incidence of small renal masses: a need to reassess treatment effect. J Natl Cancer Inst 2006;98:1331-1334.

7 Pettus JA, Jang TL, Thompson RH, et al: Effect of baseline glomerular filtration rate on survival in patients undergoing partial or radical nephrectomy for renal cortical tumors. Mayo Clin Proc 2008;83:1101-1106.

8 Go AS, Chertow GM, Fan D, et al: Chronic kidney disease and the risks of death, cardiovascular events, and hospitalization. $\mathrm{N}$ Engl J Med 2004;351:1296-1305.

-9 Simmons MN, Weight CJ, Gill IS: Laparoscopic radical versus partial nephrectomy for tumors $>4 \mathrm{~cm}$ : intermediate-term oncologic and functional outcomes. Urology 2009;73: 1077-1082.
10 Joudi FN, Allareddy V, Kane CJ, et al: Analysis of complications following partial and total nephrectomy for renal cancer in a population based sample. J Urol 2007;177:17091714.

11 Passos VMA, Assis TD, Barreto SM: Hypertension in Brazil: estimates from populationbased prevalence studies. Epidemiol Serv Saude 2006;15:35-45.

12 Passos VM, Barreto SM, Diniz LM, et al: Type 2 diabetes: prevalence and associated factors in a Brazilian community - the Bambuí health and aging study. Sao Paulo Med J 2005;123: 66-71.

13 Barlow LJ, Korets R, Laudano M, et al: Predicting renal functional outcomes after surgery for renal cortical tumours: a multifactorial analysis. BJU Int 2010;106:489-492.

14 Clark AT, Breau RH, Morash C, et al: Preservation of renal function following partial or radical nephrectomy using 24-hour creatinine clearance. Eur Urol 2008;54:143-149.

15 Luo JH, Zhou FJ, Xie D, et al: Analysis of longterm survival in patients with localized renal cell carcinoma: laparoscopic versus open radical nephrectomy. World J Urol 2010;28:289293.

16 Antoniewicz AA, Poletajew S, Borowka A, et al: Renal function and adaptive changes in patients after radical or partial nephrectomy. Int Urol Nephrol 2012;44:745-751.
17 Lau WK, Blute ML, Weaver AL, et al: Matched comparison of radical nephrectomy vs nephron-sparing surgery in patients with unilateral renal cell carcinoma and a normal contralateral kidney. Mayo Clin Proc 2000;75:12361242.

18 Scosyrev E, Messing EM, Sylvester R, et al: Renal function after nephron-sparing surgery versus radical nephrectomy: results from EORTC randomized trial 30904. Eur Urol 2014;65:372-377.

19 Lane BR, Novick AC, Babineau D, et al: Comparison of laparoscopic and open partial nephrectomy for tumor in a solitary kidney. J Urol 2008;179:847-851; discussion 852.

20 Takagi T, Kondo T, Iizuka J, et al: Predictors for postoperative renal function after open partial nephrectomy: including postoperative biomarkers. Int J Urol 2012;19:823-828.

21 Foyil KV, Ames CD, Ferguson GG, et al: Longterm changes in creatinine clearance after laparoscopic renal surgery. J Am Coll Surg 2008;206:511-515.

22 Godoy G, Ramanathan V, Kanofsky JA, et al: Effect of warm ischemia time during laparoscopic partial nephrectomy on early postoperative glomerular filtration rate. J Urol 2009; 181:2438-2443; discussion 2443-2445.

23 Arceo-Olaiz R, de la Morena JM, Hernan$\operatorname{dez} \mathrm{V}$, et al: The role of ischemia in the deterioration of renal function after partial nephrectomy. Arch Esp Urol 2013;66:350358. 